\title{
Improving Employee Engagement: Making the Case for Planned Organizational Change Using the Burke-Litwin Model of Organizational Performance and Change
}

\author{
Joyce B. Boone \\ School of Business, Kaplan University USA \\ jboone@kaplan.edu
}

\begin{abstract}
This case analysis focuses on a community college program environment, which is challenged by low employee participation and engagement. The purpose of this writing is to describe an assessment and proposal for planned changed in this program based on the Burke-Litwin Model of Organizational Performance and Change (Burke, 2002). The outcome of the assessment and plan for change is a theoretically based strategy applicable to this organization and suggested for consideration by other organizations where the presenting problem (low engagement in this case) is a symptom of deeper and underlying issues related to employee morale and organizational culture. This example is submitted to promote practitioner reflection in any organization challenged by low employee engagement, participation, or involvement. The depiction of the case describes the problem, a review of alternative organizational models to address it, the selection of an appropriate model, and the plan of action, which was proposed, consisting of initiatives to address the issues at specific points within the organization.
\end{abstract}

Key Words: Change, Planned Change, Engagement, Involvement, Burke-Litwin

\section{Introduction}

A community college has appointed a working committee to a draft a grant proposal for improving teaching strategies for a small academic program. The first step in the process involved surveying the program's faculty to identify the areas in which they felt a need to be professionally developed. It should be noted that professional development was one of the components in each faculty member's annual work performance evaluation. To the surprise of the committee, the response on the departmental faculty survey was minimal, with only one-third of the faculty members responding to the survey. Even after the faculty members were informed by the college's administration that completion of the survey was mandatory, there was still minimal response from the faculty. The problem was twofold: 1) the reason for the limited feedback on the survey was unknown, and 2) there was no strategy to increase employee engagement. To resolve the problem, the primary program administrator asked an external consultant to assess the situation and propose a strategy to improve the overall participation and engagement of the program's faculty. The discussion that follows describes the assessment and proposed strategy to effect improvement in faculty engagement through the Burke-Litwin causal model for planned change (Burke, 2002).

Assumptions and Significance of the Case Analysis: A key assumption was that the program administrator's agreement to be receptive to the findings and recommendations of the consultant. It was not anticipated that the consultant would recommend a structural change in the administration of the program, including recommendation for the dismissal of any person. The significance of this writing is consistent to the consultant's goals, which were to identify and examine possible reasons for limited feedback and participation among faculty members and to identify possible courses of action. This case recognizes a bold step that differentiates leaders from managers, which requires stepping back and perceiving not only the situation (low employee engagement in this case), but also examining reasons for it and being willing to take the necessary steps to rectify it. Management addresses the systematic, daily complexities and operations of an organization, but leadership orchestrates vital changes effectively (Kotter, 1990; Kouzes \& Pozner, 2007). A manager in this case may see and hear what is going on, but a leader hears what is not making a sound, and sees what the light is not revealing (Colvard, 2003). The program heads were willing to adopt a leadership approach. 
Former Situation: Upon investigating the current situation, including interviewing faculty and staff, the consultant concluded that the limited faculty participation on the survey is symptomatic of a deeper problem within the department at the climate level, at best, and is not representative of the problem itself. When interviewed by the consultant regarding the background and history of the culture and climate of the department and program, several long-term employees reported that the department had a previous culture of openness and positive "energy". The program's leadership was very visible and it was not unusual for them to ask for faculty's opinions, views, and input on issues. In a given semester, interviewees reported that they would physically see the department's and program's leadership on a regular basis, as they exhibited a MBWA (management by walking around) style. Employees were encouraged to interact freely with administrators, students, the community, and with one another. There was an open door policy relative to communication styles up, down, and across the organization. Reward systems were closely tied to achievement and overall job performance.

Current Situation: Using the program employees' description of the previous organizational culture, the consultant interviewed employees to identify the current state of the same variables, including communication and employees' interpretation of the "energy" of the department and program. When asked about the visibility of the leadership, employees reported that most communication from was via impersonal methods such as e-mail and memos. In a given semester, they reported that they may see the leadership once or twice, and most likely it is within a formal setting which did not seem to be an appropriate context to voice their questions and opinions. McCabe and Lewin (1992) define voice as consisting of two components. These are the expression of grievances or complaints in a work context by employees to management and the participation of employees in organizational decision-making. Employees' perceived lack of voice was manifesting on both of these fronts: their lack of feedback on the survey, which was connected to organizational decisions about professional development, and their reluctance to express complaints to management. Regarding the current communication system within the organization, in contrast to the past, the communication network had become increasingly linear, with an emphasis on the importance of following the chain of command. The free-flow of communication appeared to have submerged into an informal network or "grapevine", characterized by gossip, fear, rumor, and distrust, contributing to the existing atmosphere of low morale among many employees. Reward systems no longer appeared to be tied to achievement and overall job performance, but appeared to be linked to informal social networks, driven by competition for recognition by the department's and program's administrators. During an interview with a member of the leadership team, the leader relayed that as long as employees do their jobs and avoid discussing issues that they do not have all of the pertinent information about, they do not have to be concerned about not getting a contract for the next academic year. The idea of communicating with the employees to break down communication barriers did not appear to be a viable option, perpetuating the wall of partition between leadership and employees. While all leadership is inherently manipulative in some way by virtue of its inherent power, coercive power strengthens resistance, thereby perpetuating an impasse and a stagnation of innovation and creativity (Greenleaf, 1977). The absence of open communication was occurring simultaneously with a decrease in the free-flow of ideas and creativity, fostering an organizational climate of stagnation and hesitation.

What drove this change? An examination of factors that drove the change between the previous culture of openness and the current culture of diminished participation reveals two events that affected the system as a whole. These were the replacement of the department chair and an unrelated but controversial issue concerning one of the program heads. These events prompted criticism from the college environment outside of the department as well as within the department and its various programs, faculty, students, and staff. The program leaders were attempting to carry on business as usual amid an atmosphere of intense scrutiny on the part of multiple stakeholders, including area businesspersons, the press, former and potential students and employees of the department. The department's image was weakened as a result, both internally and externally.

Bases Indicating a Need for Change: The department and its programs quickly became linear in structure. Most employees interviewed rated their work performance as lower than they would like it to be due to an overall feeling of diminished morale. Literature from a similar case study revealed that an atmosphere characterized by a directive rather than facilitative leadership style resulted in a poor relationship between 
management and employees and a feeling of diminished empowerment among employees (Gardiner, 1999). While any shift involving the corporate culture of an organization is expected to bring about feelings of discomfort among those affected, at least temporarily, workplaces with more engaged employees have better outcomes in terms of lower rates of employee turnover and higher customer loyalty, higher earnings, and increased productivity (Thomas \& MacDiarmid, 2004).

\section{Opportunities for Positive Change}

Burke-Litwin Model: In considering theoretical planned change models that apply to situation, the BurkeLitwin Causal Model (Burke, 2002) was deemed an appropriate model with which to approach this case. Litwin concluded from his early work that employee performance and morale were linked to organizational climate. He also claimed that there is a positive relationship between a good work climate and high organizational performance (Litwin, 1968). It is on these ideas and research that the Burke-Litwin model was developed. In considering the model, the top half of the model focuses on transformational factors and the bottom half is relevant to transactional factors. It appears that the entire organization is affected in this case, thus requiring some degree of change in both transactional (day-to-day) and transformational (deep structure) levels of the organization. To steer the department and program toward positive transformational and transactional changes, the proposed model would serve as a framework to address the current situation vs. the desired outcomes.

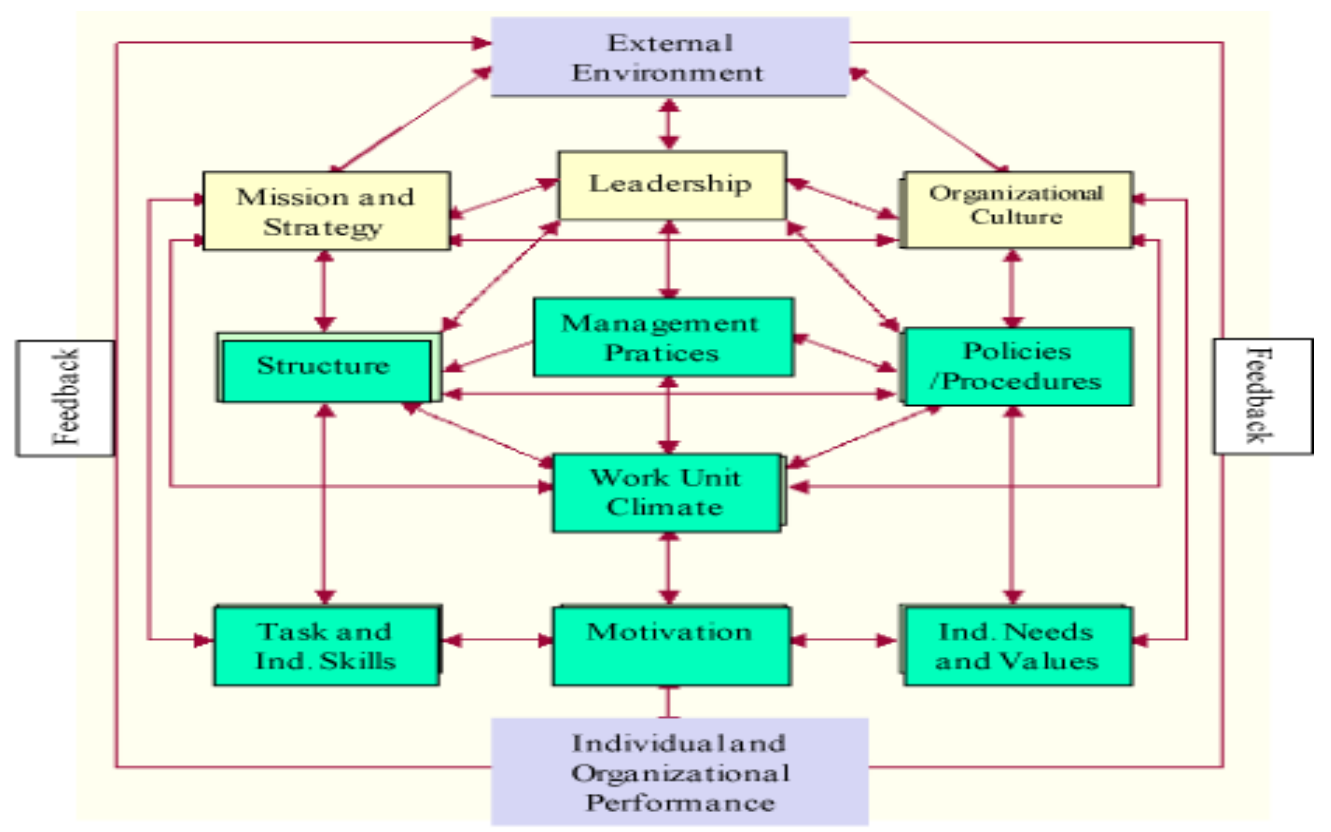

Figure 2. Model of Organizational Performance and Change Sources: Burke and Litwin (2002, p. 119).

Plan of Action: Working with department and program leaders, the consultant identified areas within each component of the Burke-Litwin model, which, if addressed, are believed to promote change within that component and subsequently create positive linkages to other components within the organization. The leadership agreed to move forward with these initiatives and communicate the same to the employees. Data is to be collected from employees via the survey method. An initial survey will serve as a way to capture baseline data regarding employees' perceptions and ratings of whether undertaking these initiatives by the organization would create a better atmosphere (improved morale and personal willingness to participate) for the employees. Each employee will subsequently complete surveys to measure perceptions of the workplace climate regarding morale and personal willingness to participate at the end of one year, three years, and five years. Considering each applicable variable in the model, the consultant and leadership established the following initiatives, with a corresponding purpose/goal statement as detailed below: 


\section{Mission and Vision Initiative}

Faculty and staff (the term employees are used interchangeably) will collaboratively arrive at a new or revised mission and vision statement for the organization.

Purpose/Goal: Giving faculty and staff a voice in the development of mission and vision statements will promote a sense of empowerment and ownership of the organization's destiny among the employees. Employees more readily accept and take ownership of resolutions that come from their peers.

\section{Structure Initiatives:}

- Department and Program leadership, with the assistance of the consultant, will identify strengths, weaknesses, opportunities, and threats into the existing strategic plan and articulate the same to the employees.

- $\quad$ Each program will perform an analysis identifying the strengths, weaknesses, opportunities, and threats of the program/department and communicate same above, beneath, and across the organization.

\section{Purpose/Goals:}

- A SWOT analysis will provide a clearer understanding of the program's strengths, weaknesses, opportunities, and threats. Particularly, employees will become more aware of their internal resources by considering the program's strengths and weaknesses. They will also feel that they are being brought into the communication loop and, and as a result, may begin to more trust of the departmental and program leadership.

- SWOT (analysis of strengths, weaknesses, opportunities, and threats) on the departmental level will empower the program heads and administrators by making them more aware of environment and industry variables. Particularly as a result of identifying the department's opportunities and threats, department heads and administrators will be empowered to position the program within its competitive and macro environments (Bateman \& Snell, 2009).

Leadership Initiative: Leadership will receive training stressing the difference between leading and managing. Purpose/Goal: Seeing the leadership become more visible, and model the desired behavior (participation, improved morale) that they expect of others in the organization, employees will receive a powerful statement from leadership and will likely be perceived as reaching out to the human side of the organization. The current state of low morale and seeming defensiveness on many levels will begin to thaw or shift.

\section{Management Practices Initiatives:}

- Communications systems will become more open, frequent, and formal organization-wide, with opportunity to ask questions and provide feedback. Clayson advises that leadership must be willing to distribute information from a standpoint of facilitation and cultivation (2004). Distributed information will empower employees by creating a channel for two-way communication, allowing for feedback in both vertical directions within the organization (Bateman \& Snell, 2009) New distribution of information among employees should include information that will increase employees' learning capability and enable them to develop their potential (Ezzamel, Lilley, \& Willmott, 1994).

- Development of detailed, written human resources materials, which includes protocol for applying for promotions or other movement within the organization, as well as other viable human resources, functions.

\section{Purpose/Goals:}

- Communication of important information and input on vital decisions will no longer be provided along an informal network, but will be incorporated into the norms of the organization. This will alleviate problems associated with the current over-reliance on the "office grapevine" and presumption, rumor, innuendo.

- 2. The creation of a human resources department will formalize and articulate uniform policies and procedures for human resources activities, as well as provide a venue with uniform procedures and protocol for employee grievances in human resources matters. 
Work Unit Climate Initiative: Department heads will have formal communication protocol with program chairs, reinforcing the objectives and mission, thereby promoting the desired culture of the department.

Purpose/Goals: Program chairs will carry on the new culture/climate from department chairs and communicate same information and energy to instructors, line staff, and indirectly, to the students, perpetuating the new climate of the organization.

Organizational Culture Initiative: Employees will take initial survey, providing data that will serve as a baseline for future comparison of survey data.

Purpose/Goals: The initial survey will provide information regarding employees' perception of the initiatives and how these initiatives will impact their views of the workplace and readiness to participate in these and other initiatives.

\section{Policies/Procedures Initiative:}

- Performance Review of each program.

- Reward systems should be closely tied to performance and achievement.

\section{Purpose/Goal:}

- Performance Review will provide a measurement of the degree to which each program's performance is meeting its prescribed objectives.

- Rewards (promotions, fringe benefits) tied to individual and group achievement would promote employee motivation and teamwork, and reduce cliques and turfism in the workplace network dynamic. Employees could begin to more confidently match the needs of the program and department to their individual strengths, values, and needs.

\section{Consideration of Three Alternative Organizational Models}

Weisbord's Six-Box Model: In the case of the program department, Weisbord's model (Weisbord, 1976) would indeed be applicable, considering that the model acknowledges both the formal and informal aspects of each component of his model: purposes, relationships, leadership, structure, helpful mechanisms, and rewards. Within the program department, there appears to be an overwhelming reliance on the informal aspects of many of the components, as opposed to relying on formal protocol and uniform procedures. This appears to have created much of the mistrust among employees and low morale overall. Weisbord contends that positive organizational change is made possible by "reducing the gap" between formal and informal aspects of each component, which easily and simply creates a visual or mental image of where the organization is compared to where it is trying to move. In the current case, however, the movement toward positive change required a deeper analysis of the current vs. desired situation, and a more thorough and complete coverage of each aspect of the organization. This was facilitated through the Burke-Litwin model of planned change (2002).

Nadler-Tushman Congruence Model: While the Nadler-Tushman Congruence Model (1977) is very relevant in terms of its approach to inputs and outputs of and how they affects the organization and its environment, the complexity of this model presents a possible barrier to the movement toward positive change in the current case. Not only would it be complex and abstract in terms of the consultant explaining it to the administration and soliciting their support to implement an action plan, it would also be, in most cases, too cumbersome for the employees to be receptive to attempt to buy-in to the changes. The Burke-Litwin model (2002) represented a sufficiently thorough, yet relatively easy-to-explain process that all can understand and assimilate.

Tichy's TPC (Technical, Political, and Cultural) Framework: Tichy's (1983) model is a comprehensive organizational change model that includes most critical variables to understanding organizational change. This model appears most applicable when facilitating change primarily focusing on the functional or macro areas and focusing less on individual factors. Tichy's model identifies nine components in the organization from a functional approach and creates a framework to consider how they interact with technical, political, and cultural constructs in the organization's internal and external environments. Since the primary focus in this case was to address issues related to the organizational culture at the staff, department, and program 
levels, the Burke Litwin model's (2002) incorporation of culture, leadership, and mission provided an approach that aligned more appropriately with the immediate need.

Potential Barriers to Change: The successful implementation of change requires a genuine dedication on the part of employees and leadership. A cynical view of the change attempts can thwart the process. Leadership and the consultant would be wise to acknowledge the possibility of cynicism to change attempts in the organization. If there is a prevailing atmosphere of cynicism within the organizational climate, even the most sincere of attempts at change will not likely have a chance to become successful (Wanous, Reichers, \& Austin, 2000).

Employee Perspective: Resistance to change can slow down or sabotage the change process. Core attitudinal changes among employees are required. With regard to employees, it is expected that participation will increase over time. Initially, employees may be hesitant to state their true impressions and opinions. Over the past few years, a sense of insecurity has developed among the employees, which will take some time to reverse. For positive change from the employees' perspective, they must also be willing to shift from a system of competitive relationships to a teamwork approach, characterized by collaborative working relationships (Bateman \& Snell, 2009).

Leadership Perspective: Resistance to change among the department and program's leadership can also create a barrier to change. Attitudes among leadership must be one of a willingness to share power and decentralize. To begin to gain momentum, leadership must be willing to shift their focus toward teamwork and team building. Most importantly, they must be willing to model the desired behavior and adopt an attitude of stewardship and a participative management style. An atmosphere of administrative stewardship is characterized by a controlled distribution of power as opposed to an attempt to control the people in the organization. The result is an empowerment of the employees as well as a feeling of ownership of the destiny of the organization among its employee (Block, 1993). Leaders who have met the challenge of controlled distribution of power among employees have found that the payoff of more productive and loyal employees far outweighs their sacrifice (Dawson, 1999). The assessment of the case involved obtaining descriptions of the previous and current corporate cultures of the organization, comparing the two, and asking relevant questions to ascertain what drove the change between past and present culture. This was a crucial question, because it allowed the consultant to identify the conditions that precipitated the current conditions that were manifesting at that time. The consultant was able to identify a core issue that involved the culture of the organization and required an integrated model approach to address the complex issue of how to provoke planned change. The Burke-Litwin model was selected as the appropriate approach, and a plan of action was proposed, consisting of initiatives, which addressed specific components of the organization that affected the corporate culture. Each initiative includes the directive and the corresponding purpose. Potential barriers to the success of the change plan were then explored, consisting of mainly deep issues concerning participant attitudes.

\section{Conclusion}

Although the consultant did not interact with the program throughout the entire implementation of the strategy, solutions to the two-fold problem of 1) identifying the cause of low employee involvement, and 2) development of a strategy to increase employee engagement were realized. A post-test using the initial survey which was used during the assessment period would be an effective way to gauge whether any significant improvement in employee perceptions have occurred as a result of implementation of the plan. A worthy endeavor would also involve comparing employee and even student performance after implementation to determine whether there was any measureable change. The experience, however, helped everyone involved to see that planned change is possible and that it can produce positive and predictable results. They also became aware that change requires a joint commitment to improve and a willingness to work together. Immediate or presenting issues require exploration for deeper meanings and connections. Often, temporary solutions are applied to presenting symptoms that are only demonstrative of the true, underlying problem. Identification of the real problem is critical to the organization's ability to position itself to resolve that problem and its accompanying issues or presenting symptoms. In a bureaucratic organization such as an academic department of a community college, it is often helpful to consider strategies for 
employee empowerment, allowing for differences in interpretation and implementation, and focus more on the end result more than the method used. Changes involving the deep structure or culture of an organization require an investment of time and support on multiple levels. These changes often involve issues that are tangent to individual core values. These are deep issues and the changes will not occur overnight. Organizations often include networks and ties built on power, loyalties, and precautions, all which may or may not be built on truth. An effective examination of the deep structure of an organization's climate requires a team approach and a support system that spans a broad range of time and individuals. The critical issues facing today's managers and leaders are often not only situated in questions about task and structure, but also questions of spirit (Hawley, 1993).

\section{References}

Bateman, T. \& Snell, S. (2009). Management, 8th edition. New York: McGraw-Hill.

Block, P. (1993). Stewardship: Choosing service over self-interest. San Francisco: Berrett-Koehler.

Burke, W. W. (2002). Organization change: Theory and practice. Thousand Oaks, California: Sage Publications

Clayson, T. (2004). New relationship needed as workplace loyalty fades. Materials Management and Distribution, 49(8), 85.

Colvard, J. (2003). Managers vs. Leaders, taken from Govexec.com (www.govexec.com/dailyfed/htm) on $6 / 04 / 2012$.

Dawson, K. (1999). Your work life is what you make it. The Journal for Quality and Participation, 22(1) 48-52.

Ezzamel, M., Lilley, S. \& Willmott, H. (1994). The new organization and the new managerial work. European Management Journal, 12(4) 454-61.

Gardiner, P., (1999). Soaring to new heights with learning oriented companies. Journal of Workplace Learning, 11(7) 255.

Greenleaf, R. K. (1977). Servant leadership. New York: Paulist Press.

Hawley, J. (1993). Reawakening the spirit in work. New York: A Fireside Book.

Kotter, J. P. (1990). What leaders really do? Harvard Business Review, 68, 103-111.

Kouzes, J. \& Pozner, B. (2007). The leadership challenge. San Francisco: Jossey-Bass.

McCabe, D. \& Lewin, D. (1992). Employee voice: A human resource management perspective. California Management Review, 32(3), 112-123.

Litwin, G. H. \& Stringer, R. A. (1968). Motivation and organizational climate. Boston: Harvard Business School Press.

Maclagen, P. (1988). Management and morality: A developmental perspective. London: Sage.

Nadler, D. \& Tushman, M. (1977). A diagnostic model for organization behavior. In J. Hackman, E. Lawler III, and L. Porter (Eds.), Perspectives in behavior in organizations. (85-100). New York: McGraw-Hill.

O’Toole, J. (1995). Leading change: The argument for values-based leadership. New York: Ballentine Books.

Thomas, A. \& MacDiarmid, A. (2004). Encouraging employee engagement. CMA Management, 78, 14-16.

Tichy, N. M. (1983). Managing strategic change: Technical, political, and cultural dynamics. New York: Wiley.

Wanous, J., Reichers, A. \& Austin, J. (2000). Cynicism about organizational change. Group and Organization Management, 25, 132-154.

Weisbord, M. (1976). Organizational diagnosis: Six planes to look for trouble with or without a theory. Group and Organization Studies, 1, 430-447. 